\title{
Dietary intervention with green dwarf banana flour (Musa sp. AAA) modulates oxidative stress and colonic SCFAs production in the TNBS model of intestinal inflammation
}

\author{
L.D. Almeida-Junior, T.F.S. Curimbaba, A.S. Chagas, A.E.V. Quaglio, L.C. Di Stasi* \\ Laboratory of Phytomedicines, Pharmacology and Biotechnology (PhytoPharmaTech), Department of Pharmacology, Institute of Biosciences, Universidade Estadual Paulista \\ UNESP, Botucatu, São Paulo CEP 18618-970, Brazil
}

\section{A R T I C L E I N F O}

\section{Article history:}

Received 9 June 2017

Received in revised form 6 September 2017

Accepted 14 September 2017

Available online 27 September 2017

\section{Keywords:}

Banana

Musa sp. AAA

Short Chain Fatty Acids (SCFA)

Inflammatory Bowel Disease (IBD)

Acetate

Propionate

Butyrate

\begin{abstract}
A B S T R A C T
Dietary products with prebiotic properties have been used to promote protective effects during inflammatory process. Prebiotics are source of short chain fatty acids (SCFAs) that have been associated with anti-inflammatory effects. Banana (Musa sp. AAA) is rich in resistant starch, which is used by colonic microbiota to SCFAs production. For this, we used the trinitrobenzenesulphonic acid model of intestinal inflammation to evaluate whether intestinal anti-inflammatory effect is related to prebiotic effects. Dietary intervention with green dwarf banana flour (5\% or $10 \%$ ) increased acetate, propionate and butyrate concentration. The protective effects was also evidenced by reduction in extension of lesion, inhibition of myeloperoxidase activity, prevention in glutathione depletion, increased mucin production and mucosal healing. This way, dietary green dwarf banana modulates oxidative stress and colonic production of SCFAs increasing intestinal tissue protection and may be used as a complementary product to prevent or avoid relapse of symptoms in inflammatory bowel diseases.
\end{abstract}

(c) 2017 Elsevier Ltd. All rights reserved.

\section{Introduction}

Inflammatory Bowel Disease (IBD) includes Ulcerative colitis (UC) and Crohn's disease (CD), chronic inflammatory disorders of the gastrointestinal tract, both characterized by periods of exacerbation of symptoms followed by prolonged intervals of remission (Maloy \& Powrie, 2011). An exaggerated and inappropriate mucosal immune response mediated by mucosal $\mathrm{T}$ cells triggers synthesis and release of pro-inflammatory mediators, including reactive species of oxygen and nitrogen, and cytokines such as TNF- $\alpha$, IL-6, IL-1 $\beta$, INF- $\gamma$ and IL-10 (Muzes, Molnar, Tulassay, \& Sipos, 2012).

Intestinal homeostasis depends on complex interactions among genetic, environmental, microbial and immune factors; however, the miscommunication between the gut microbiota and intestinal mucosal immune system results in the failure of mucosal homeostasis (Maloy \& Powrie, 2011; Muzes et al., 2012). Dysbiosis has been considered an important immunologic aetiology factor in IBD, where quantitative and qualitative changes in the microbial composition have been reported (Shim, 2013). Changes of intestinal microbiota promoted by genetic, environmental factors such as infections, use of antibiotics and low dietary fibre intake may

\footnotetext{
* Corresponding author.

E-mail address: Idistasi@ibb.unesp.br (L.C. Di Stasi).
}

contribute to defective host immunity (Ananthakrishnan, 2015; Ananthakrishnan et al., 2013; Galvez, Rodriguez-Cabezas, \& Zarzuelo, 2005; Rodriguez-Cabezas et al., 2010; Shim, 2013).

Prebiotics, defined as non-digestible food ingredients that beneficially affect the host by selectively stimulating the growth and/or the activity of limited bacteria in the colon, have increasingly been used to treat or prevent gastrointestinal disorders (Looijer-van Langen \& Dieleman, 2009; Meyer, 2015). Indeed, several prebiotics, such as dietary fibre, can be fermented by specific colonic bacteria to produce several metabolites such as short-chain fatty acids (SCFAs) mainly acetate, propionate and butyrate, lactic acid and gas (Meyer, 2015).

Approximately $95 \%$ of the SCFAs, originating from microbiota fermentation, are absorbed into the bloodstream generating systemic actions, lowering blood lipid levels, flattening effect on postprandial blood glucose, modulating neutrophil chemotaxis and phagocytosis, apoptosis and immune response by different pathways (Macfarlane \& Macfarlane, 2011; Meyer, 2015). These actions are closely related to anti-inflammatory, anti-tumour, anti-obesity, dyslipidemic, anti-diabetic and antimicrobial activities (Brownawell et al., 2012; Tan et al., 2014). These findings highlight SCFAs as key players in maintenance of gut and immune homeostasis.

Considering prebiotics can be a source of SCFAs in the body, several dietary products rich in non-digestible components are 
potential candidates to treat or prevent chronical diseases such as diabetes, obesity, metabolic syndrome and inflammatory bowel disease. Based on this, our laboratory has been interested in studying the protective effects afforded by functional foods against intestinal inflammatory process (Fruet, Seito, Rall, \& Di Stasi, 2012; Scarminio, Fruet, Witaicenis, Rall, \& Di Stasi, 2012; Witaicenis, Fruet, Salem, \& Di Stasi, 2010) with special interest in tropical foods, among which dwarf banana (Musa sp. AAA) was selected because its fruits in immature state are rich in dietary fibre and starch granules (Da Motta, Lajolo, Ciacco, \& Cordenunsi, 2000). Starch granules contain $73.6-79.4 \%$ of starch, out of which 47.3-54.2\% are resistant starch (Da Motta et al., 2000; Faisant et al., 1995; Hettiaratchi, Ekanayake, \& Welihinda, 2011; JuarezGarcia, Agama-Acevedo, Sayago-Ayerdi, Rodriguez-Ambriz, \& Bello-Perez, 2006; Ramos, Leonel, \& Leonel, 2009; Scarminio et al., 2012). Resistant starch is considered a dietary fibre because it is a non-digestible polysaccharide resistant to digestion and used as fermentative product by colonic microbiota to produce SCFAs (Da Motta et al., 2000; Faisant et al., 1995; Juarez-Garcia et al., 2006; Ramos et al., 2009). In fact, a previous study performed by our research group demonstrated that a dietary intervention with green dwarf banana flour produced intestinal anti-inflammatory activity reducing myeloperoxidase and alkaline phosphatase activities accompanied by counteraction of glutathione depletion in an experimental model of intestinal inflammation (Scarminio et al., 2012). Based on this, we decided to investigate whether intestinal anti-inflammatory activity of the green dwarf banana flour was related to increased short-chain fatty acid production by fermentative colonic process, acting as a prebiotic product.

\section{Methods and materials}

\subsection{Chemicals}

All chemicals were supplied by Sigma Aldrich and were freshly prepared for each biochemical evaluation and GC/MS analysis. The enriched diet with green dwarf banana flour was manufactured in the Universidade Estadual Paulista, UNESP, São Paulo, Brazil.

\subsection{Plant material and diet preparation}

Green dwarf banana fruits (Musa spp. AAA) were collected in Botucatu City, São Paulo, Brazil, in February 2014, and was cultivated in a small farmer using organic agricultural method. The plant was identified by taxonomists from Irina Delanova Gemtchujnicov Herbarium (Institute of Biosciences, São Paulo State University, UNESP), where a voucher specimen was deposited. After collection, the entire green banana fruits, including pulp and peel, were washed, chopped, and dried at $50{ }^{\circ} \mathrm{C}$ for 72 hours in a hothouse with forced air circulation and renewal. After drying, the fruits were powdered to produce flour. For the preparation of the enriched diet, the flour was added at a ratio of $5 \%$ and $10 \%$ in previously sprayed Nuvilab food for rodents by geometric dilution. After homogenization, water was added to produce a paste. The paste was then placed in a pelletizer to produce diet pellets containing $5 \%$ or $10 \%$ green dwarf banana flour.

The ingredient composition of the diets was calculated from the major nutrients of the normal Nuvilab, taking into account the addition of $5 \%$ or $10 \%$ green dwarf banana flour (Table 1 ).

\subsection{Animals}

Male Wistar rats with 21 days were obtained from ANILAB (Animais de Laboratório) in Paulínia, São Paulo (Brazil) and were housed in standard environmental conditions $\left(21^{\circ} \mathrm{C}, 60-70 \%\right.$
Table 1

Main ingredient composition of the diets fed to rats ( $\mathrm{g} / 100 \mathrm{~g})$.

\begin{tabular}{|c|c|c|c|}
\hline Ingredients & Control diet & 5\% Banana diet & 10\% Banana diet \\
\hline Protein mix & 22.0 & 20.9 & 19.8 \\
\hline Mineral mix & 10.0 & 9.5 & 9.0 \\
\hline Fiber & 8.0 & 7.6 & 7.2 \\
\hline Fat & 4.5 & 4.2 & 4.0 \\
\hline Banana flour ${ }^{b}$ & - & 5.0 & 10.0 \\
\hline
\end{tabular}

a Mineral mixture provided the following amounts (in milligrams per kilogram) Mn, 60.0; I, 2.0; Co, 1.5; Fe, 50.0; Zn, 60.0; Cu, 10.0, Se, 0.05 .

b Fruits of green dwarf banana (Musa sp. AAA) containing starch (73.6-79.4\%), amylose (20.9-23.5\%), protein (2.61-2.99\%), soluble fiber $(2.29-2.49 \%)$, insoluble fiber (5.35-5.39\%), ash (3.44-3.56), and traces of lipids (Da Motta, Lajolo, Ciacco, \& Cordenunsi, 2000) Vitamin mixture provided the following amounts (in milligrams per kilogram per diet): vitamin A (25 $200 \mathrm{UI})$; vitamin D3 (2.100 UI); vitamin E (60 mg); vitamin K (12.5 mg); vitamin B12 (60 $\mu \mathrm{g})$; vitamin B6 (12 mg); folic acid (6 mg); choline (1100 mg); biotin $(0.26 \mathrm{mg})$; niacin (60 mg); thiamine (11 mg); and pantothenic acid (112 mg).

humidity) with $12 \mathrm{~h}$ light/dark cycle and air filtration. Animals had free access to water and food. Experimental protocols met the "Guidelines of Animal Experimentation" approved by the Ethical Committee for Animal Research (Protocol number 042/04CEEA), Institute of Biosciences, Universidade Estadual Paulista (UNESP).

\subsection{Experimental design}

The rats were randomly assigned into 4 groups with 7 animals each. This number was defined considering the power of statistical test, the minimum significance and maximum deviation to observe difference among groups (Eng, 2003). Two groups were included for reference: a non-colitic group that received saline intracolonically and a colitic group that received TNBS. Two additional colitic groups received an enriched diet with $5 \%$ and $10 \%$ dwarf banana flour for 36 days. Colitis was induced using the method originally described by Morris et al. (1989). After fasting overnight, the animals were anesthetized. Under anaesthesia, they were given $10 \mathrm{mg}$ of trinitrobenzenesulphonic acid (TNBS) dissolved in $0.25 \mathrm{~mL}$ of $50 \%$ ( $\mathrm{vol} / \mathrm{vol}$ ) ethanol by means of a Teflon (Dupont, Wilmington, Del) cannula inserted $8 \mathrm{~cm}$ into the anus. During and after TNBS administration, the rats were kept in a headdown position until they recovered from the anaesthesia. Rats from the non-colitic group received $0.25 \mathrm{~mL}$ of saline. Animals from all groups were dead 2 days after colitis induction.

\subsection{Assessment of colonic damage}

Animal body weights, the occurrence of diarrhoea (as detected by perianal fur soiling), and total food intake for each group were recorded daily. Once the rats were killed, the colon was removed aseptically and adhesions occurrence between the colon and adjacent organs were noted. Then the luminal contents were collected for the short chain fatty acids studies. Colons were placed on an ice-cold plate, cleaned of fat and mesentery, blotted on filter paper and weighed and its length measured under a constant load ( $2 \mathrm{~g})$. Then it was opened longitudinally and scored for macroscopically visible damage on a 0-10 scale, according to (Bell, Gall, \& Wallace, 1995). Subsequently the colon was longitudinally divided into different pieces to be used for the determinations: myeloperoxidase (MPO), and alkaline phosphatase (ALP) activity, total glutathione (GSH) content, IL-1 $\beta$, IL-6, TNF- $\alpha$ and INF- $\gamma$ levels.

\subsection{Biochemical assays in colonic specimens}

MPO activity was measured according to the technique previously described Krawisz, Sharon, and Stenson (1984). The results 
were expressed as MPO units per $\mathrm{g}$ of wet tissue. Total GSH content was quantified with the recycling assay Anderson (1985) and the results were expressed as nmol per g of wet tissue. ALP activity was measured spectrophotometrically using disodium nitrophenyl phosphate (5.5.mM) as the substrate in $50 \mathrm{mM}$ glycine buffer containing $0.5 \mathrm{mM} \mathrm{MgCl}_{2}$, pH 10.5 Bessey, Lowry, and Brock (1946).

Colonic samples for the determinations of TNF- $\alpha$, IL-1 $\beta$, IL-6 and INF- $\gamma$ were weighed, homogenized, minced on an ice-cold plate and re-suspended in a centrifugation tube containing $10 \mathrm{mM} / \mathrm{L}$ phosphate buffered saline $\mathrm{pH} 7.4(1: 5 \mathrm{w} / \mathrm{v})$. The tubes were placed in a shaker submerged in a $37^{\circ} \mathrm{C}$ water bath for 20 minutes and then centrifuged at $9000 \mathrm{~g}$ for $5 \mathrm{~min}$ at $4{ }^{\circ} \mathrm{C}$. The supernatants were frozen at $-80^{\circ} \mathrm{C}$ until assayed. The TNF- $\alpha$, IL-1 $\beta$, IL-6 and INF- $\gamma$ levels were quantified by a DuoSet ELISA Kit to measure the concentration of the natural and recombinant rat enzyme according to the manufacturer's instructions (R\&D Systems, Inc., Minneapolis, Minnesota, USA). The results were expressed as pg per $\mathrm{ml}$.

\subsection{Preparation of faecal samples and gas chromatographic analysis}

The faecal samples were collected after death of animals and stored in plastic tube at $-80^{\circ} \mathrm{C}$. The extraction process was based on the work Garcia-Villalba et al. (2012) with modifications. Faeces were weighed and frozen at $-80^{\circ} \mathrm{C}$ immediately after collection. Once thawed, faeces were suspended in $1 \mathrm{ml}$ of phosphoric acid $0.5 \%$ per $100 \mathrm{mg}$ of sample, were homogenized with vortex for about $1 \mathrm{~min}$ and centrifuged for $10 \mathrm{~min}$ at 17,950g. Each millilitre of water supernatant was extracted with $1 \mathrm{ml}$ of ethyl acetate for $1 \mathrm{~min}$ and centrifuged for $10 \mathrm{~min}$ at $17,950 \mathrm{~g}$. Prior to analysis, a $1 \mathrm{ml}$ volume of the organic phase was transferred into a tube and octanoic acid added as internal standard (IS) at a final concentration of $755 \mu \mathrm{g} / \mathrm{ml}$. The IS was used to correct for injection variability between samples and minor changes in the instrument response. Three independent replicate extractions were performed per sample with two injections each.

Chromatographic analysis was carried out using a GC-MS Thermo Scientific, model FOCUS equipped with an automatic liquid sampler (Thermo - triplus DUO), and coupled to a Thermo ISQ 230ST mass detector. The GC was fitted with a high polarity, polyethylene-glycol fused silica capillary TG-WASMS $(30 \mathrm{~m}$, $0.25 \mathrm{~mm}$ id, $0.25 \mathrm{~m}$ film thickness) and helium was used as the carrier gas. Injection was made in split mode with an injection volume of $1 \mu \mathrm{l}$ and split flow $300 \mathrm{ml} / \mathrm{min}$. The injector temperature was $250{ }^{\circ} \mathrm{C}$. A glass liner with a glass wool plug at the lower end of the liner was used to avoid the contamination of the GC column with non-volatile faecal material. Every ten faecal samples injected a blank sample with ethyl acetate was inserted to check for memory effects. The column temperature was initially $80^{\circ} \mathrm{C}$, then increased to $120^{\circ} \mathrm{C}$ at $50^{\circ} \mathrm{C} / \mathrm{min}$, to $160^{\circ} \mathrm{C}$ at $70^{\circ} \mathrm{C} / \mathrm{min}$ and kept at this temperature for $50 \mathrm{sec}$, to $180^{\circ} \mathrm{C}$ at $70^{\circ} \mathrm{C} / \mathrm{min}$ and kept at this temperature for $1 \mathrm{~min}$, and finally to $210^{\circ} \mathrm{C}$ at $70^{\circ} \mathrm{C} / \mathrm{min}$ and kept at this temperature for $1 \mathrm{~min}$. Solvent delay was $3.5 \mathrm{~min}$. The detector was operated in electron impact ionization mode (electron energy $70 \mathrm{eV}$ ), scanning the $30-250 \mathrm{~m} / \mathrm{z}$ range. Identification of the SCFAs was based on the retention time of standard compounds and with the assistance of the NIST 08 and NIST online libraries. The peaks were quantified as the relative abundance of the total ionic count with respect to the internal standard. The concentration $(\mathrm{mg} / \mathrm{ml})$ of each SCFA was calculated using the linear regression equations $(R 2 \geq 0.99)$ from the corresponding standard curves obtained with 12 different concentrations.

\subsection{Histological evaluation}

Representative whole gut specimens were taken from a region of the inflamed colon corresponding to the segment adjacent to the gross macroscopic damage and were fixed in $4 \%$ buffered formaldehyde. The cuts, with $6 \mu \mathrm{m}$ thick were deparaffinised and rehydrated using ethyl alcohol decreasing series. Next, the samples were subjected to haematoxylin-eosin staining in for morphological analysis.

For PAS/Alcian Blue analysis was used the previously protocol described by Linden, Florin, and McGuckin (2008). De-waxed sections were immersed in $100 \%$ ethanol for $10 \mathrm{~min}$, rinsed in water for $10 \mathrm{~min}$, immersed in 3\% acetic acid for $2 \mathrm{~min}$ and stained in $1 \%$ Alcian Blue 8GX in 3\% acetic acid ( $\mathrm{pH} 2.5$ ) for $2.5 \mathrm{~h}$. Nonspecific stain was removed with $3 \%$ acetic acid and rinsed in water for $10 \mathrm{~min}$. The slides were then oxidized in $1 \%$ periodic acid in water at room temperature for $10 \mathrm{~min}$, washed in water for $5 \mathrm{~min}$, immersed in Schiff's reagent for $10 \mathrm{~min}$, rinsed in water for $5 \mathrm{~min}$ and then three times in $0.5 \%$ sodium meta-bisulphite before a final wash in water. To reveal O-acetylated oligosaccharides sections were first treated with $0.1 \mathrm{M} \mathrm{KOH}$ for $30 \mathrm{~min}$ and then $1 \mathrm{mM}$ periodic acid prior to the Schiff reagent.

After staining, images were subjected to analysis and photomicrography with a Leica microscope utilizing Leica Qwin Plus version 3.3 e 3.40 .

\subsection{Statistical analyses}

Parametric data are expressed as the mean \pm S.E.M., and the differences between means were tested for statistical significance using one-way analysis of variance (ANOVA). Nonparametric data (score) are expressed as the median (range) and were analysed with the Kruskal-Wallis test. Statistical significance was set at $\mathrm{p} \leq 0.05$.

\section{Results}

TNBS administration resulted in colonic inflammation, which was demonstrated after 2 days by severe necrosis of the mucosa, typically extending $4.2-7.2 \mathrm{~cm}$ along the colon, bowel wall thickening, and hyperaemia (Table 2). This inflammatory process reduced food intake and loss of body weight (data not shown). The macroscopic analysis in the TNBS-control group revealed the existence of severe necrosis and inflammation of the mucosa, extending along the colon. In addition, all animals showed adherence of the colon with adjacent organs. This characterizes the colonic inflammation, which was also evidenced by an increase in weight/length ratio when compared with non-colitic (Table 2). Banana diet $10 \%$ reduced the extension of lesion compared to the TNBS-control group, furthermore both 5 and $10 \%$ presented minor adhesion (Table 2).

Biochemically, the colonic damage was characterized by a 20-fold increase in colonic MPO and 3-fold increase in AP activities (Table 3 ), as well as in increased TNF- $\alpha$, IL-1 $\beta$ and IL-6 colonic levels (Table 4). Furthermore, significant colonic GSH depletion took place in the inflamed colon (Table 3). Treatment of animals with banana diet 5 and 10\% significantly reduced MPO activity and counteracted GSH depletion (Table 3), but no effects were observed on the cytokines production (Table 4).

Analysis of the short-chain fatty acids production after treatment with dietary intervention with green dwarf banana was performed by gas chromatography and mass spectrometry. Intestinal inflammatory process induced by TNBS produced a lower concentration of SCFAs in relation to non-colitic group with better reduction on the acetate production (Fig. 1). Dietary intervention with green dwarf banana flour at $5 \%$ increased 2 -fold butyrate and propionate colonic concentration and 5-fold acetate when compared with the TNBS-control group (Fig. 1). On the other hand, dietary intervention with green dwarf banana flour at $10 \%$ 
Table 2

Effects of the Banana diet (5\% or 10\%) in macroscopic parameters in intestinal inflammation induced by trinitrobenzenosulfonic acid.

\begin{tabular}{|c|c|c|c|c|}
\hline Group & Damage score $(0-10)^{\mathrm{a}}$ & Extension of damage $(\mathrm{cm})^{\mathrm{b}}$ & Weight/length ratio $(\mathrm{mg} / \mathrm{cm})^{\mathrm{b}}$ & Adherence (\%) \\
\hline Non-colitic & $0^{* *}$ & $0.0 \pm 0.0^{* *}$ & $90.4 \pm 2.5^{* *}$ & $0.0^{* *}$ \\
\hline TNBS-control & $10(8-10)$ & $5.5 \pm 0.5$ & $173.8 \pm 6.9$ & 100.0 \\
\hline Banana diet $5 \%$ & $8(7-9)$ & $4.0 \pm 0.4$ & $164.0 \pm 5.1$ & 51.1 \\
\hline Banana diet $10 \%$ & $8(7-10)$ & $3.7 \pm 0.5^{*}$ & $182.3 \pm 14.4$ & 42.8 \\
\hline
\end{tabular}

a Score data are expressed as the median (range).

b Extension of lesion and weight/length ratio data are expressed as the mean \pm S.E.M.

c Adherence were analysed by Fisher's exact test ${ }^{*} \mathrm{p}<0.05$ and ${ }^{* *} \mathrm{p}<0.01$ vs TNBS-Control group.

Table 3

Effects of the Banana diet (5\% or 10\%) on myeloperoxidase (MPO), glutathione (GSH) content and alkaline phosphatase (ALP) activities in intestinal inflammation induced by trinitrobenzenosulfonic acid.

\begin{tabular}{llll}
\hline Group & $\begin{array}{l}\text { MPO } \\
(\mathrm{U} / \mathrm{g} \text { tissue })\end{array}$ & $\begin{array}{l}\text { GSH } \\
(\mathrm{nmol} / \mathrm{g} \text { tissue })\end{array}$ & $\begin{array}{l}\text { ALP } \\
(\mathrm{mU} / \mathrm{mg} \text { protein })\end{array}$ \\
\hline Non-colitic & $122.6 \pm 11.8^{* *}$ & $1153.0 \pm 29.4^{* *}$ & $3.9 \pm 0.2^{* *}$ \\
TNBS-control & $2591.0 \pm 120.1$ & $440.0 \pm 87.3$ & $11.6 \pm 1.0$ \\
Banana diet 5\% & $1865.0 \pm 168.2^{* *}$ & $1029.0 \pm 108.1^{* *}$ & $12.8 \pm 2.0$ \\
Banana diet 10\% & $2016.0 \pm 241.0^{* *}$ & $896.0 \pm 127.2^{* *}$ & $9.7 \pm 1.7$ \\
\hline
\end{tabular}

Data are expressed as mean \pm S.E.M. ${ }^{*} \mathrm{p}<0.05$ and ${ }^{* *} \mathrm{p}<0.01$ vs TNBS-Control group.

increased 2-fold and 5-fold propionate and acetate colonic concentration (Fig. 1). Although colonic butyrate concentration was increased with this dietary intervention, the effects was not statistical significant.

In the histological analysis, the non-colitic group presented a mucosa containing numerous straight tubular glands with many lightly stained goblet cells; crypt and luminal epithelium was intact with a typical morphology associated with normal villus. In TNBS-control group tubular glands with normal crypt were reduced with loss of membrane integrity and the goblet cells were atypical with extensive oedema and a large area of ulceration. Dietary intervention with banana at $5 \%$ and $10 \%$ recovery the colon cell architecture including the restoration of mucosa with straight tubular glands with normal crypt, which were similar to healthy animals; oedema was reduced and villus was preserved (Fig. 2). In Alcian Blue/PAS photomicrographs the non-colitic group presented several mucous cells containing mixed acid and neutral mucins, combined with a membrane-bound mucus layer. In the TNBS-control group notes a large reduction of mucus and the number of goblet cells. Banana diet group both $5 \%$ and $10 \%$ showed a higher proportion of mucus producing cell in relation to the TNBS control group and a greater amount of mucus in the intestinal lumen from the banana flour (Fig. 3).

\section{Discussion}

Dwarf banana in immature state is a promising fruit that has been studied due to its high composition of dietary fibre and resistant starch (Juarez-Garcia et al., 2006; Ramos et al., 2009; Scarminio et al., 2012). Intestinal anti-inflammatory activity of dietary green dwarf banana flour has been previously described by our research group (Scarminio et al., 2012); however, there is no evidence whether protective effect against intestinal inflammatory process is dependent on prebiotic effect or produced by other mechanisms. In the present study, we demonstrated that dietary green dwarf banana flour intervention increased the colonic production of acetate, propionate and butyrate when compared with TNBS-control animals, acting as a prebiotic product. Previous studies also showed that consumption of banana fibres increases the concentration of SCFAs in healthy human volunteers and this increase was related to an improvement of the body functions (Mitsou et al., 2011).

Several compounds from natural origin, mainly dietary fibre and resistant starch, can be fermented by specific colonic bacteria and converted into SCFAs, which after absorption display a lot of mechanisms of action, producing systemic immunomodulatory and anti-inflammatory properties, particularly useful on IBD treatment (Meyer, 2015; Topping \& Clifton, 2001; Vinolo, Rodrigues, Nachbar, \& Curi, 2011). SCFAs are a group of simple 2-carbon to 5-carbon fatty acids produced by anaerobic micro-organisms mainly from poly-, oligo- and fructo-saccharides, proteins, peptides and glycoprotein precursors (Richards, Li, van Esch, Garssen, \& Folkerts, 2016; Tan \& O'Toole, 2015). The most abundant SCFAs in the colon are acetate, propionate and butyrate, which are considered active metabolites, stimulating regulatory $\mathrm{T}$ cells, reducing inflammatory mediators and increasing gut barrier function (Fernández et al., 2016). In the cecum and large intestine, 95\% of the SCFAs are rapidly absorbed by the colonocytes while the remaining 5\% are secreted in the faeces (den Besten et al., 2013; Topping \& Clifton, 2001). Faecal presence of SCFAs is a fermentative metabolite indicator that can be used as a biomarker of the nutritional interventions (Garcia et al., 2008; Garcia-Villalba et al., 2012). Huda-Faujan et al. (2010) showed that there is a decrease of SCFAs in patients with intestinal inflammation, results similar to what happened with rats of TNBS-control group.

Besides banana flour effects on the SCFAs production, we also observed that dietary green dwarf banana intervention produced protective effects on the intestinal inflammatory process, modulating oxidative stress. The antioxidative properties were evidenced by reduced MPO activity and counteracted GSH depletion. In fact, intestinal inflammation is accompanied by excessive production of reactive oxygen and nitrogen metabolites (Kruidenier \& Verspaget, 1998). In the oxidative stress process there is an imbalance between the generation of reactive oxygen species and the antioxidant defence mechanisms, leading to a cascade of reactions in which lipids, proteins and/or DNA may get damaged

Table 4

Effects of the Banana diet (5\% or 10\%) on cytokines levels in intestinal inflammation induced by trinitrobenzenosulfonic acid.

\begin{tabular}{|c|c|c|c|c|}
\hline Group & $\operatorname{IL1} \beta(\rho \mathrm{g} / \mathrm{ml})$ & IL6 $(\rho g / m l)$ & TNF- $\alpha(\rho g / m l)$ & IFN- $\gamma(\rho \mathrm{g} / \mathrm{ml})$ \\
\hline Non-colitic & $1151.0 \pm 103.9^{* *}$ & $344.8 \pm 33.9^{* *}$ & $39.2 \pm 4.2^{* *}$ & $48.8 \pm 21.1$ \\
\hline TNBS-control & $4284.0 \pm 384.5$ & $857.6 \pm 120.9$ & $70.3 \pm 8.6$ & $50.6 \pm 18.3$ \\
\hline Banana diet 5\% & $4655.0 \pm 413.1$ & $849.5 \pm 137.3$ & $66.6 \pm 6.0$ & $52.9 \pm 5.4$ \\
\hline Banana diet $10 \%$ & $4203.0 \pm 104.9$ & $553.4 \pm 65.9$ & $81.3 \pm 6.0$ & $70.4 \pm 9.9$ \\
\hline
\end{tabular}

Data are expressed as mean \pm S.E.M. ${ }^{*} \mathrm{p}<0.05$ and ${ }^{*} \mathrm{p}<0.01$ vs TNBS-Control group. 

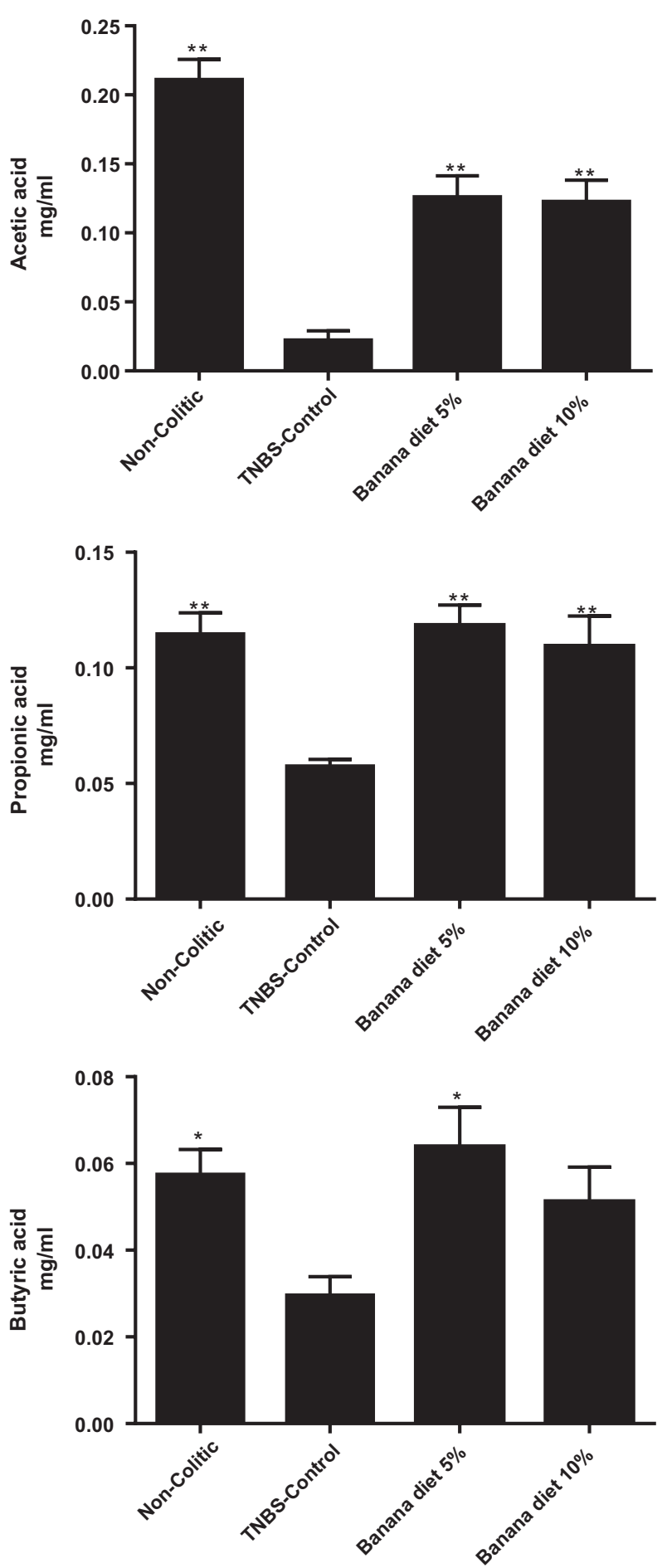

Fig. 1. Concentration ( $\mathrm{mg} / \mathrm{ml}$ wet faeces) of the SCFAs in rat faecal samples. Values are expressed as the mean value \pm S.E.M. $\mathrm{p}<0.05$ and ${ }^{* *} \mathrm{p}<0.01$ vs TNBS-Control group.

(Hamer et al., 2009). MPO plays a central role in inflammation and oxidative stress, exerting deleterious effects through multiple pathways (Hamer et al., 2009). It is found in the neutrophil azurophilic granules, acting as an infiltration marker of these cells, so activity reduction in this enzyme is related to lower cellular infiltration into the colon (Krawisz et al., 1984; Winterbourn \& Brennan, 1997). Besides acting as a neutrophil infiltration marker, MPO also generates reactive intermediates, leading to oxidative damage of protein and lipids (Karakas \& Koenig, 2012; Krawisz et al., 1984). In our study, both proportions of banana dietary intervention were able to decrease MPO activity, indicating lower neutrophil infiltration. In fact, Maslowski et al. (2009) showed a suggestive inhibitory effect of these fatty acids on neutrophil migration in response to chemoattractant.

Associated to inhibitory MPO activity, the dietary intervention with banana flour at proportions of $5 \%$ and $10 \%$ avoided the colonic GSH depletion induced by intestinal inflammation. GSH is an important component of the antioxidant defence and a lack of GSH has been shown to result in severe degeneration of intestinal epithelial cells in mice (DeLeve \& Kaplowitz, 1991; Masella, Di Benedetto, Vari, Filesi, \& Giovannini, 2005). GSH supplementation decreases colonic damage by promoting its restoration as well as cysteine levels and, therefore, decreases lipid peroxidation in experimental model of colitis induced by TNBS (Loguercio et al., 2003). GSH plays a key role eliminating reactive oxygen species and maintaining cellular redox balance, leading to a reduction of oxidative stress (Loguercio et al., 2003).

Our results were similar to previous results described by our research group (Scarminio et al., 2012) and those demonstrate that banana flour was able to preserve GSH content and catalase activities (Kaimal, Sujatha, \& George, 2010; Vijayakumar, Presannakumar, \& Vijayalakshmi, 2008). A reduction in the oxidative stress by decreasing MPO activity and preservation of GSH content can be also interpreted as a manifestation of the intestinal anti-inflammatory effect exerted by fibre in this model of experimental colitis.

We also observed, by histological evidences, that dietary intervention with banana flour increased the barrier function in colon tissue, reducing epithelial damage and facilitating mucosal healing. Mucosal healing is related to reduce likelihood of clinical relapse, risk of surgery and hospitalization levels (Neurath \& Travis, 2012). Since mucosal healing is a tightly controlled process associated with suppression of inflammation and improvement of intestinal barrier function (Neurath \& Travis, 2012), products able to increase this effect are very important and potentially useful to use in patients with IBD. Indeed, the inhibition of MPO activity and neutralization of GSH depletion evidenced in our study indicated that there is less oxidative stress leading to a better tissue recovery. According to Morita, Tanabe, Sugiyama, Kasaoka, and Kiriyama (2004), resistant starch ingestion reinforced mucosal protection against the attack of TNBS. This way, it is possible to suggest that protective effects promoted by green dwarf banana flour were partially related to presence of resistant starch in banana flour. Indeed, improved barrier function and mucosal healing were also related to increased mucin production induced by banana flour. Since mucins may be involved in mechanisms of epithelium growth and protection as well as in the repair of altered epithelium (Burger-van Paassen et al., 2009; Corfield et al., 2000), dietary intervention with green dwarf banana flour can be also acting by the enhancement of intestinal epithelial barrier function.

Histological analysis revealed that fibre supplementation promoted a faster recovery of damaged colonic mucosa with an evident presence of epithelial regeneration, associated with the fact that the groups treated with the dietary fibre showed higher cell integrity. In addition with the improvement in histological characteristics, the $10 \%$ banana flour diet group had a lower extension of lesion, compared with the TNBS control group, reinforcing that tissue damage was lower in the groups receiving dietary fibre. The SCFAs production by fermentation of green banana dietary fibre could be related to the decreased permeability, favouring the epithelial tissue integrity, as shown in the histological analysis and lower extension of lesion. Several studies showed that SCFAs are the main energy source for enterocytes and stimulate cell proliferation to ensure the integrity of the intestinal mucosa, reducing the risk of intestinal diseases (Vinolo et al., 2011). Ohata, Usami, 


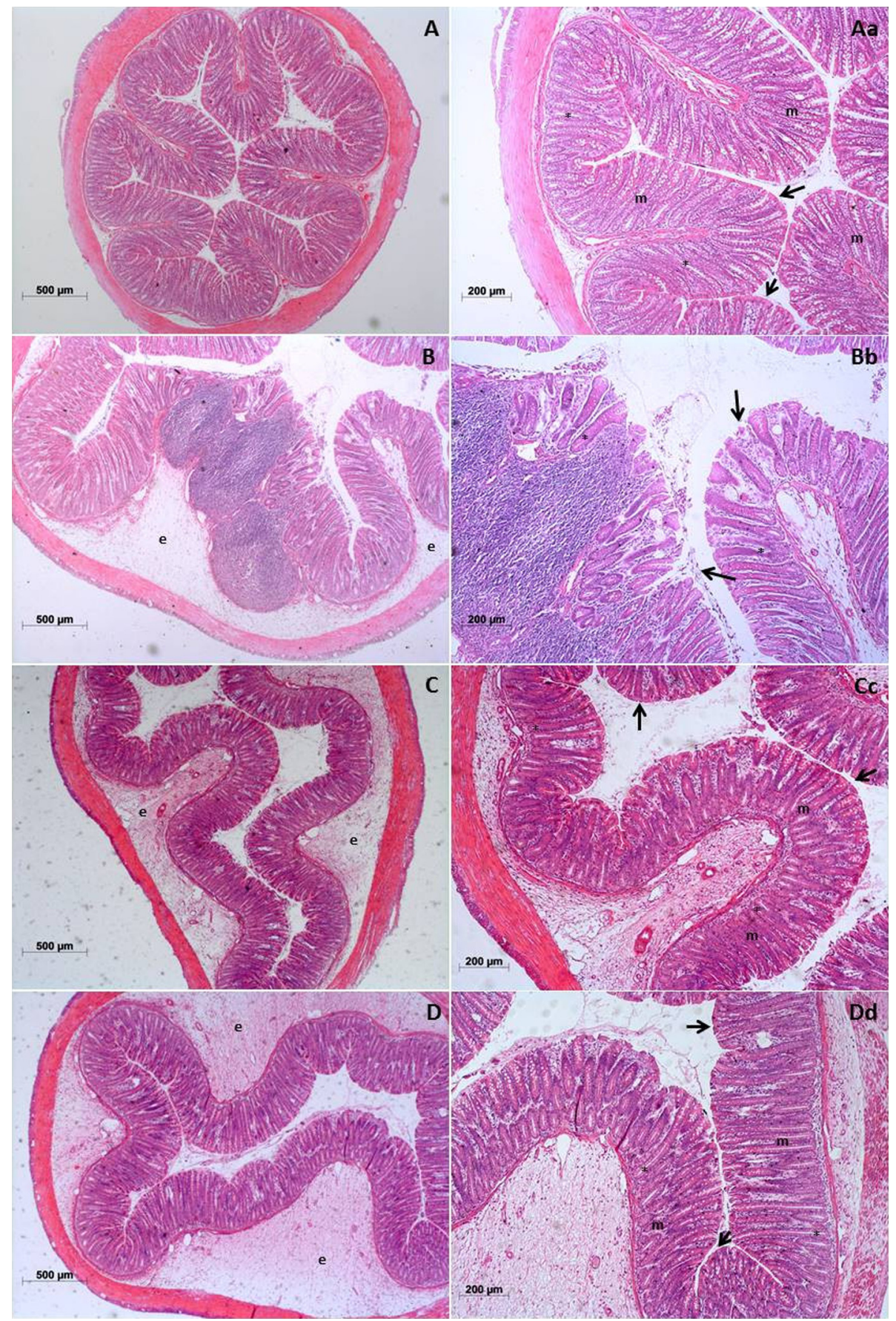

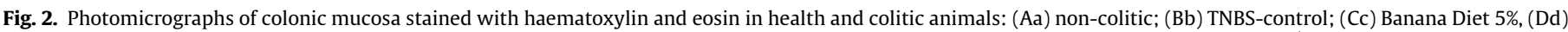

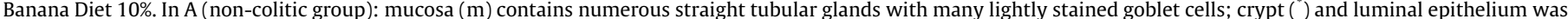

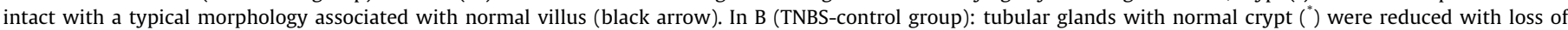

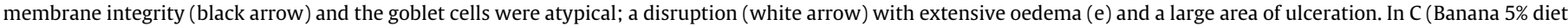

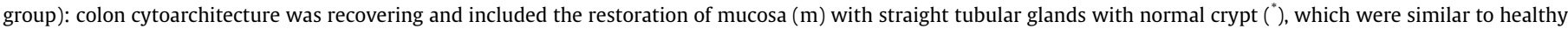

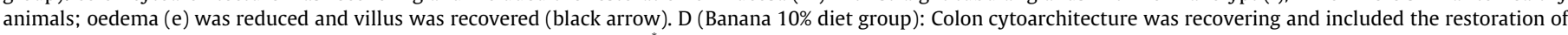
mucosa $(\mathrm{m})$ and tubular glands, lightly stained goblet cells and crypt $\left.{ }^{*}\right)$ preserved.

and Miyoshi (2005) showed in their study that butyrate and propionate decrease the permeability of the membrane to increase the tight junctions. SCFAs may be crucial elements not only for colonocytes but also for endothelial cells (Miyoshi, Usami, \& Ohata, 2008).

It has been described that SCFAs production by fermentation also regulates the functions of almost every type of immune cells, altering gene expression, differentiation, chemotaxis, proliferation, apoptosis and increasing proinflammatory cytokine production by different mechanisms (Sun, Wu, Liu, \& Cong, 2016). Advanced studies show that free fatty acid receptors with high expression in immune cells are important regulators of $\mathrm{T}$ cell function, suggesting that high fibre induced-diet activates these receptors, which are critical for intestinal homeostasis (Koh, De Vadder, Kovatcheva-Datchary, \& Backhed, 2016; Macia et al., 2015; Maslowski et al., 2009). SCFAs also regulate cytokine expression in T cells and generation of regulatory T cells (Tregs) through histone deacetylases inhibition (Koh et al., 2016). Although all these effects can be induced by different prebiotics, we observed that 


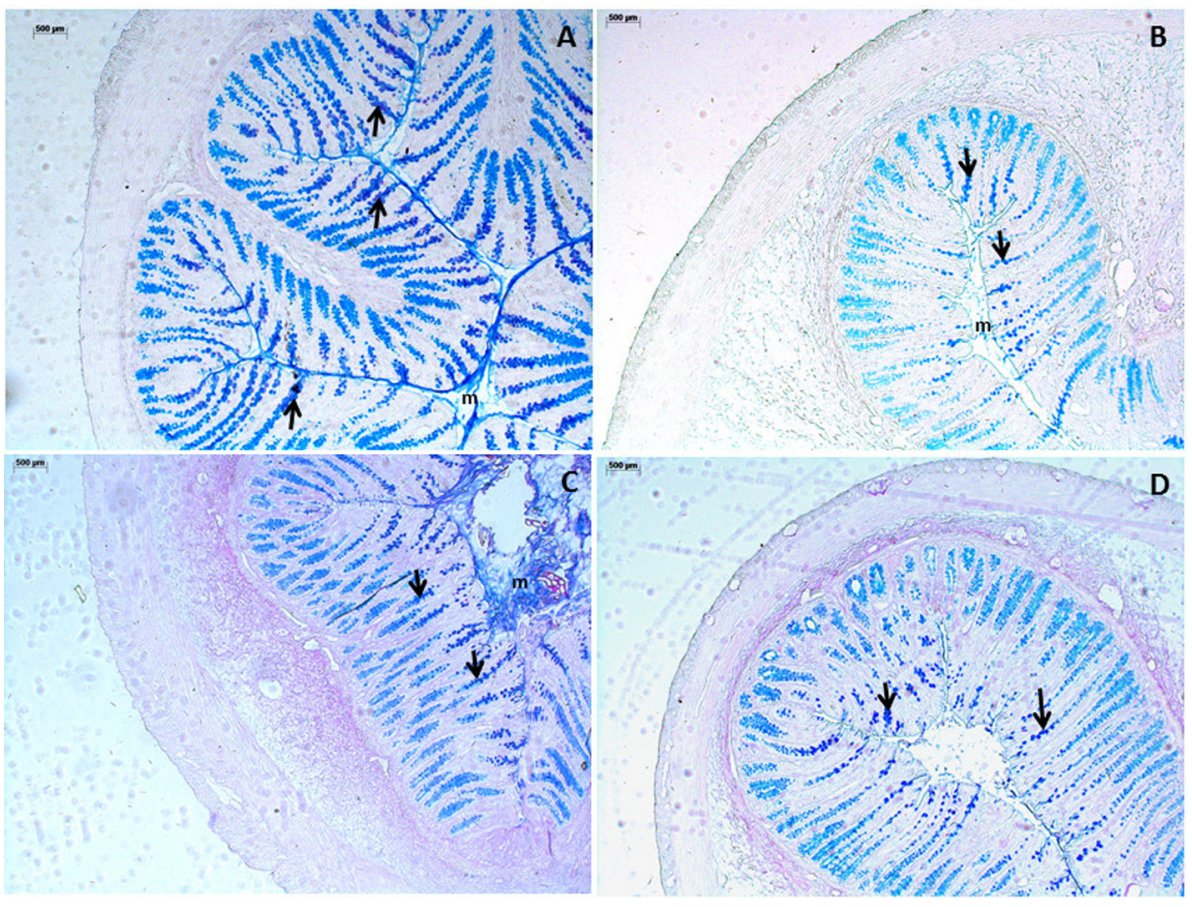

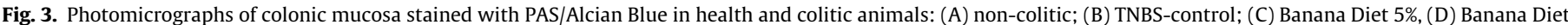

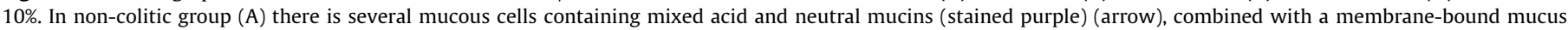

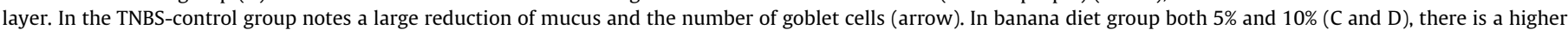
proportion of mucus producing cell in relation to the TNBS control group (arrow), and a greater amount of mucus in the intestinal lumen from the banana flour $5 \%$ ( $\mathrm{m}$ ).

dietary intervention with green dwarf banana flour was not able to affect TNF- $\alpha$, IL1- $\beta$, IL- 6 and INF- $\gamma$ production. On the other hand, new studies are necessary to evaluate the effects of banana flour on other cytokines production in other experimental conditions.

Although Scarminio et al. (2012) reported that protective effects of green dwarf banana flour was not related to an increase in total content of lactic bacteria, our results clearly demonstrated that banana flour increased the SCFAs production probably by prebiotic effects induced by the presence of resistant starch, modulating the growth and development of specific intestinal microbiota bacteria. No immunomodulatory effects were observed after dietary intervention, but protective effects of banana flour were related to its antioxidative properties and by the improvement in mucosal healing and mucin production in the colon, contributing to greater tissue integrity in animals after treatment.

Banana is an abundant fruit in most countries of the world, widely available, with low cost, and easily accessed by world population. In addition, the production of green dwarf banana flour is simple by drying and pulverizing. Based on this, the use of whole fruit as a dietary complementary product in patients with IBD is a promising and innovative approach to improve life quality of these patients, when associated with intestinal antiinflammatory drugs. Although our results showed that dietary intervention with green dwarf banana flour is an intestinal antiinflammatory approach acting by prebiotic, antioxidative and mucosal healing effects, new studies must be performed in order to compare these effects associated with current drugs used to treat IBD and to determine its detailed mechanisms of action.

\section{Acknowledgements}

Research in the Di Stasi Lab (PhytoPharmaTech) was supported by Fundação de Amparo à Pesquisa do Estado de São Paulo (FAPESP), grant number 15/15267-8 and 11/50512-2. Fellowships: Quaglio and Di Stasi from National Council for Scientific and Technological Development (CNPq -Brazilian Ministry of Science and
Technology), Chagas, Curimbaba and Almeida-Junior from Coordination for the Improvement of Higher Education Personnel (CAPES), Brazilian Ministry of Education.

\section{References}

Ananthakrishnan, A. N. (2015). Epidemiology and risk factors for IBD. Nature Reviews Gastroenterology \& Hepatology, 12(4), 205-217. https://doi.org/10.1038/ nrgastro.2015.34.

Ananthakrishnan, A. N., Khalili, H., Konijeti, G. G., Higuchi, L. M., de Silva, P., Korzenik, J. R., \& Chan, A. T. (2013). A prospective study of long-term intake of dietary fiber and risk of Crohn's disease and ulcerative colitis. [Research Support]. Gastroenterology, 145(5), 970-977. https://doi.org/10.1053/ j.gastro.2013.07.050.

Anderson, M. E. (1985). Determination of glutathione and glutathione disulfide in biological samples. Methods in Enzymology, 113, 548-555.

Bell, C. J., Gall, D. G., \& Wallace, J. L. (1995). Disruption of colonic electrolyte transport in experimental colitis. [Research Support, Non-U.S. Gov't]. American Journal of Physiology, 268(4 Pt 1), G622-630.

Bessey, O. A., Lowry, O. H., \& Brock, M. J. (1946). A method for the rapid determination of alkaline phosphates with five cubic millimeters of serum. Journal of Biological Chemistry, 164, 321-329.

Brownawell, A. M., Caers, W., Gibson, G. R., Kendall, C. W., Lewis, K. D., Ringel, Y., \& Slavin, J. L. (2012). Prebiotics and the health benefits of fiber: Current regulatory status, future research, and goals. Journal of Nutrition, 142(5), 962-974. https:// doi.org/10.3945/jn.112.158147.

Burger-van Paassen, N., Vincent, A., Puiman, P. J., van der Sluis, M., Bouma, J., Boehm, G., \& Renes, I. B. (2009). The regulation of intestinal mucin MUC2 expression by short-chain fatty acids: Implications for epithelial protection. Biochemical Journal, 420(2), 211-219. https://doi.org/10.1042/BJ20082222.

Corfield, A. P., Myerscough, N., Longman, R., Sylvester, P., Arul, S., \& Pignatelli, M. (2000). Mucins and mucosal protection in the gastrointestinal tract: New prospects for mucins in the pathology of gastrointestinal disease. Gut, 47(4), 589-594.

Da Motta, R. V., Lajolo, F. M., Ciacco, C., \& Cordenunsi, B. R. (2000). Composition and functional properties of banana flour from different varieties. Starch-Starke, 53, 63-68.

DeLeve, L. D., \& Kaplowitz, N. (1991). Glutathione metabolism and its role in hepatotoxicity. Pharmacology \& Therapeutics, 52(3), 287-305.

den Besten, G., van Eunen, K., Groen, A. K., Venema, K., Reijngoud, D. J., \& Bakker, B. M. (2013). The role of short-chain fatty acids in the interplay between diet, gut microbiota, and host energy metabolism. Journal of Lipid Research, 54(9), 2325-2340. https://doi.org/10.1194/jlr.R036012.

Eng, J. (2003). Sample size estimation: How many individuals should be studied? Radiology, 227(2), 309-313. 
Faisant, N., Buleon, A., Colonna, P., Molis, C., Lartigue, S., Galmiche, J. P., \& Champ, M. (1995). Digestion of raw banana starch in the small intestine of healthy humans: Structural features of resistant starch. British Journal of Nutrition, 73(1), $111-123$.

Fernández, J., Redondo-Blanco, S., Gutiérrez-del-Río, I., Miguélez, E. M., Villar, C. J., \& Lombó, F. (2016). Colon microbiota fermentation of dietary prebiotics towards short-chain fatty acids and their roles as anti-inflammatory and antitumour agents: A review. Journal of Functional Foods, 25, 511-522. https://doi.org/ 10.1016/j.jff.2016.06.032.

Fruet, A. C., Seito, L. N., Rall, V. L., \& Di Stasi, L. C. (2012). Dietary intervention with narrow-leaved cattail rhizome flour (Typha angustifolia L.) prevents intestinal inflammation in the trinitrobenzenesulphonic acid model of rat colitis. BMC Complementary and Alternative Medicine, 12, 62. https://doi.org/10.1186/14726882-12-62.

Galvez, J., Rodriguez-Cabezas, M. E., \& Zarzuelo, A. (2005). Effects of dietary fiber on inflammatory bowel disease. Molecular Nutrition \& Food Research, 49(6), 601-608. https://doi.org/10.1002/mnfr.200500013.

Garcia, A., Olmo, B., Lopez-Gonzalvez, A., Cornejo, L., Ruperez, F. J., \& Barbas, C. (2008). Capillary electrophoresis for short chain organic acids in faeces Reference values in a Mediterranean elderly population. Journal of Pharmaceutical and Biomedical Analysis, 46(2), 356-361. https://doi.org/ 10.1016/j.jpba.2007.10.026.

Garcia-Villalba, R., Gimenez-Bastida, J. A., Garcia-Conesa, M. T., Tomas-Barberan, F. A., Carlos Espin, J., \& Larrosa, M. (2012). Alternative method for gas chromatography-mass spectrometry analysis of short-chain fatty acids in faecal samples. Journal of Separation Science, 35(15), 1906-1913. https://doi. org/10.1002/jssc.201101121.

Hamer, H. M., Jonkers, D. M., Bast, A., Vanhoutvin, S. A., Fischer, M. A., Kodde, A., \& Brummer, R. J. (2009). Butyrate modulates oxidative stress in the colonic mucosa of healthy humans. Clinical Nutrition, 28(1), 88-93. https://doi.org/ 10.1016/j.clnu.2008.11.002.

Hettiaratchi, U. P., Ekanayake, S., \& Welihinda, J. (2011). Chemical compositions and glycemic responses to banana varieties. International Journal of Food Sciences and Nutrition, 62(4), 307-309. https://doi.org/10.3109/09637486.2010.537254.

Huda-Faujan, N., Abdulamir, A. S., Fatimah, A. B., Anas, O. M., Shuhaimi, M., Yazid, A. M., \& Loong, Y. Y. (2010). The impact of the level of the intestinal short chain Fatty acids in inflammatory bowel disease patients versus healthy subjects. Open Biochemistry Journal, 4, 53-58. https://doi.org/10.2174/ 1874091X01004010053.

Juarez-Garcia, E., Agama-Acevedo, E., Sayago-Ayerdi, S. G., Rodriguez-Ambriz, S. L., \& Bello-Perez, L. A. (2006). Composition, digestibility and application in breadmaking of banana flour. Plant Foods for Human Nutrition, 61(3), 131-137. https://doi.org/10.1007/s11130-006-0020-x.

Kaimal, S., Sujatha, K. S., \& George, S. (2010). Hypolipidaemic and antioxidant effects of fruits of Musa AAA (Chenkadali) in alloxan induced diabetic rats. Indian Journal of Experimental Biology, 48(2), 165-173.

Karakas, M., \& Koenig, W. (2012). Myeloperoxidase production by macrophage and risk of atherosclerosis. Current Atherosclerosis Reports, 14(3), 277-283. https:// doi.org/10.1007/s11883-012-0242-3.

Koh, A., De Vadder, F., Kovatcheva-Datchary, P., \& Backhed, F. (2016). From dietary fiber to host physiology: Short-chain fatty acids as key bacterial metabolites. Cell, 165(6), 1332-1345. https://doi.org/10.1016/j.cell.2016.05.041.

Krawisz, J. E., Sharon, P., \& Stenson, W. F. (1984). Quantitative assay for acute intestinal inflammation based on myeloperoxidase activity. Assessment of inflammation in rat and hamster models. Gastroenterology, 87(6), 1344-1350.

Kruidenier, L., \& Verspaget, H. W. (1998). Antioxidants and mucosa protectives: Realistic therapeutic options in inflammatory bowel disease? Mediators of Inflammation, 7(3), 157-162. https://doi.org/10.1080/09629359891081.

Linden, S. K., Florin, T. H., \& McGuckin, M. A. (2008). Mucin dynamics in intestinal bacterial infection. PLOS ONE, 3(12), e3952. https://doi.org/10.1371/journal. pone.0003952.

Loguercio, C., D’Argenio, G., Delle Cave, M., Cosenza, V., Della Valle, N., Mazzacca, G., \& Del Vecchio Blanco, C. (2003). Glutathione supplementation improves oxidative damage in experimental colitis. Digestive and Liver Disease, 35(9), 635-641. https://doi.org/10.1016/s1590-8658(03)00379-7.

Looijer-van Langen, M. A., \& Dieleman, L. A. (2009). Prebiotics in chronic intestinal inflammation. Inflammatory Bowel Diseases, 15(3), 454-462. https://doi.org/ $10.1002 /$ ibd.20737.

Macfarlane, G. T., \& Macfarlane, S. (2011). Fermentation in the human large intestine: Its physiologic consequences and the potential contribution of prebiotics. Journal of Clinical Gastroenterology, 45(Suppl), S120-127. https:// doi.org/10.1097/MCG.0b013e31822fecfe.

Macia, L., Tan, J., Vieira, A. T., Leach, K., Stanley, D., Luong, S., ... Mackay, C. R. (2015). Metabolite-sensing receptors GPR43 and GPR109A facilitate dietary fibreinduced gut homeostasis through regulation of the inflammasome. Nature Communications, 6, 6734. https://doi.org/10.1038/ncomms7734.

Maloy, K. J., \& Powrie, F. (2011). Intestinal homeostasis and its breakdown in inflammatory bowel disease. Nature, 474(7351), 298-306. https://doi.org/ $10.1038 /$ nature10208.
Masella, R., Di Benedetto, R., Vari, R., Filesi, C., \& Giovannini, C. (2005). Novel mechanisms of natural antioxidant compounds in biological systems: Involvement of glutathione and glutathione-related enzymes. Journal of Nutritional Biochemistry, 16(10), 577-586. https://doi.org/10.1016/j. jnutbio.2005.05.013.

Maslowski, K. M., Vieira, A. T., Ng, A., Kranich, J., Sierro, F., Yu, D., ... Mackay, C. R. (2009). Regulation of inflammatory responses by gut microbiota and chemoattractant receptor GPR43. Nature, 461(7268), 1282-1286. https://doi. org/10.1038/nature08530.

Meyer, D. (2015). Health benefits of prebiotic fibers. Advances in Food and Nutrition Research, 74, 47-91. https://doi.org/10.1016/bs.afnr.2014.11.002.

Mitsou, E. K., Kougia, E., Nomikos, T., Yannakoulia, M., Mountzouris, K. C., \& Kyriacou, A. (2011). Effect of banana consumption on faecal microbiota: A randomised, controlled trial. Anaerobe, 17(6), 384-387. https://doi.org/10.1016/ j.anaerobe.2011.03.018.

Miyoshi, M., Usami, M., \& Ohata, A. (2008). Short-chain fatty acids and trichostatin A alter tight junction permeability in human umbilical vein endothelial cells. Nutrition, 24(11-12), 1189-1198. https://doi.org/10.1016/j.nut.2008.06.012.

Morita, T., Tanabe, H., Sugiyama, K., Kasaoka, S., \& Kiriyama, S. (2004). Dietary resistant starch alters the characteristics of colonic mucosa and exerts protective effect on trinitrobenzene sulfonic acid-induced colitis in rats. Bioscience, Biotechnology, and Biochemistry, 68(10), 2155-2164. https://doi.org/ 10.1271/bbb.68.2155.

Morris, G. P., Beck, P. L., Herridge, M. S., Depew, W. T., Szewczuk, M. R., \& Wallace, J L. (1989). Hapten-induced model of chronic inflammation and ulceration in the rat colon. Gastroenterology, 96(3), 795-803.

Muzes, G., Molnar, B., Tulassay, Z., \& Sipos, F. (2012). Changes of the cytokine profile in inflammatory bowel diseases. World Journal of Gastroenterology, 18(41), 5848-5861. https://doi.org/10.3748/wjg.v18.i41.5848.

Neurath, M. F., \& Travis, S. P. (2012). Mucosal healing in inflammatory bowel diseases: A systematic review. Gut, 61(11), 1619-1635. https://doi.org/10.1136/ gutjnl-2012-302830.

Ohata, A., Usami, M., \& Miyoshi, M. (2005). Short-chain fatty acids alter tight junction permeability in intestinal monolayer cells via lipoxygenase activation. Nutrition, 21(7-8), 838-847. https://doi.org/10.1016/j.nut.2004.12.004.

Ramos, D. P., Leonel, M., \& Leonel, S. (2009). Amido resistente em farinha de banana verde. Alimentos e Nutricão Araraquara, 20(ISSN 0103-4235), 479-483.

Richards, L. B., Li, M., van Esch, B. C. A. M., Garssen, J., \& Folkerts, G. (2016). The effects of short-chain fatty acids on the cardiovascular system. PharmaNutrition 4(2), 68-111. https://doi.org/10.1016/j.phanu.2016.02.001.

Rodriguez-Cabezas, M. E., Camuesco, D., Arribas, B., Garrido-Mesa, N., Comalada, M. Bailon, E., \& Zarzuelo, A. (2010). The combination of fructooligosaccharides and resistant starch shows prebiotic additive effects in rats. Clinical Nutrition, 29(6), 832-839. https://doi.org/10.1016/j.clnu.2010.05.005.

Scarminio, V., Fruet, A. C., Witaicenis, A., Rall, V. L., \& Di Stasi, L. C. (2012). Dietary intervention with green dwarf banana flour (Musa sp. AAA) prevents intestinal inflammation in a trinitrobenzenesulfonic acid model of rat colitis. Nutrition Research, 32(3), 202-209. https://doi.org/10.1016/j.nutres.2012.01.002.

Shim, J. O. (2013). Gut microbiota in inflammatory bowel disease. Pediatric Gastroenterology, Hepatology \& Nutrition, 16(1), 17-21. https://doi.org/ 10.5223/pghn.2013.16.1.17.

Sun, M., Wu, W., Liu, Z., \& Cong, Y. (2016). Microbiota metabolite short chain fatty acids, GPCR, and inflammatory bowel diseases. Journal of Gastroenterology. https://doi.org/10.1007/s00535-016-1242-9.

Tan, J., McKenzie, C., Potamitis, M., Thorburn, A. N., Mackay, C. R., \& Macia, L. (2014). The role of short-chain fatty acids in health and disease. Advances in Immunology, 121, 91-119. https://doi.org/10.1016/B978-0-12-8001004.00003-9.

Tan, H., \& O'Toole, P. W. (2015). Impact of diet on the human intestinal microbiota Current Opinion in Food Science, 2, 71-77. https://doi.org/10.1016 j.cofs.2015.01.005.

Topping, D. L., \& Clifton, P. M. (2001). Short-chain fatty acids and human colonic function: Roles of resistant starch and nonstarch polysaccharides. Physiological Reviews, 81(3), 1031-1064.

Vijayakumar, S., Presannakumar, G., \& Vijayalakshmi, N. R. (2008). Antioxidant activity of banana flavonoids. Fitoterapia, 79(4), 279-282. https://doi.org/ 10.1016/j.fitote.2008.01.007.

Vinolo, M. A., Rodrigues, H. G., Nachbar, R. T., \& Curi, R. (2011). Regulation of inflammation by short chain fatty acids. Nutrients, 3(10), 858-876. https://doi org/10.3390/nu3100858.

Winterbourn, C. C., \& Brennan, S. O. (1997). Characterization of the oxidation products of the reaction between reduced glutathione and hypochlorous acid. Biochemical Journal, 326(Pt 1), 87-92.

Witaicenis, A., Fruet, A. C., Salem, L., \& Di Stasi, L. C. (2010). Dietary polydextrose prevents inflammatory bowel disease in trinitrobenzenesulfonic acid model of rat colitis. Journal of Medicinal Food, 13(6), 1391-1396. https://doi.org/10.1089/ jmf.2009.0275. 